The Journal of Public Space

2017 | Vol. 2 n. 3 Special Issue

https://www.journalpublicspace.org

\title{
VIEWPOINT
}

\section{FESTA Festival of Transitional Architecture in Christchurch, New Zealand}

Jessica Halliday

Te Pütahi, New Zealand

Christchurch Centre for Architecture and City-making

jessica@festa.org.nz

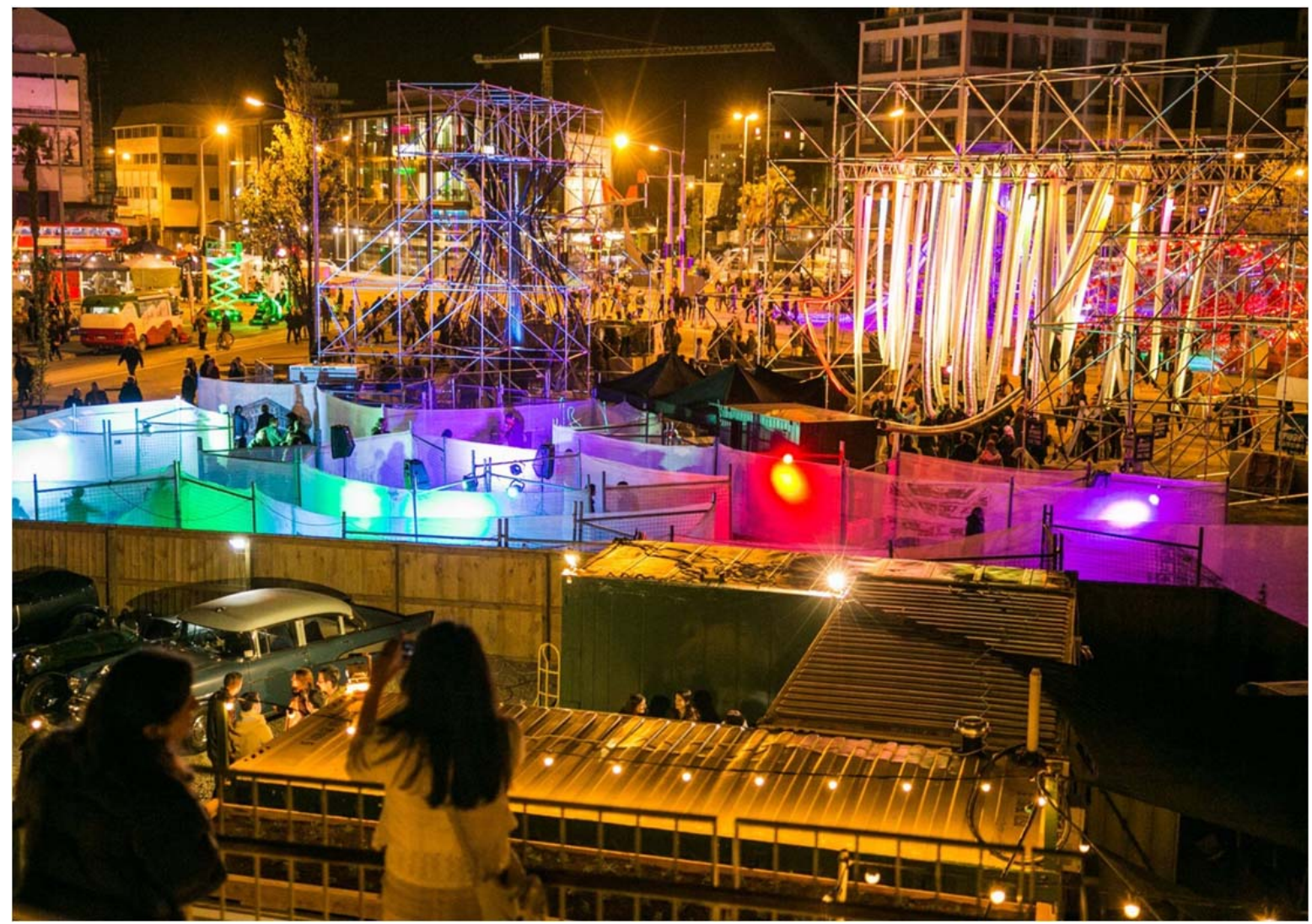

Figure I. CityUps, FESTA 20 I4. Photo: Erica Austin.

In 2012 FESTA' emerged in Christchurch, New Zealand as a collective response to the extraordinary circumstances of a natural disaster. As a place-based (and now biennial) weekend-long festival of architecture and urbanism it continues to seek and find relevance to that place, its people, and to all involved in the event (participants, audience, funders and supporters) as the extraordinary fades into a more ordered and ordinary existence.

\footnotetext{
I http://festa.org.nz/. Accessed October I, 2017.
} 
On 22 February 20I I, a large earthquake hit the city of Christchurch, New Zealand. It was the second largest, and most destructive, of a series of over II,000 earthquakes recorded in the region over a 2-year period from September 2010. 185 people died as a result of the February quake and over $75 \%$ of the built fabric of the central city was demolished. Christchurch's central city was cordoned off from the public and put under army control, portions of it for over two years. A new government agency was established to direct the city's recovery. It commissioned and backed a new spatial plan for the central city ('The Blueprint'), designed to retain existing land values and incentivise new and current investment as well as renew public spaces and amenities. Land damage caused whole suburban areas to be deemed unrepairable and these neighbourhoods were 'red zoned' 3 and purchased by the central government. Over 4 years, 8000 homes in the suburban red zones were demolished. Drastic change and uncertainty touched most aspects of Christchurch people's lives in the years following the earthquake.

Amid the chaos and uncertainty of disaster, citizens ${ }^{4}$ swiftly recognised the effect of losing their public buildings and institutions and the civic and cultural life they supported. The creative communities of Christchurch responded to this loss with activity in the form of myriad creative urban projects and spontaneous public events. These returned some cultural and civic life and provided positive reasons to gather in the vacant and changing public spaces of the city. New organisations spearheaded this adaptive urbanism. Gap Filler ${ }^{5}$ drew on performance practice and theory as well as architecture, while Greening the Rubble ${ }^{6}$ drew on landscape architecture practice. These two new groups weren't the only people active in this way as other artists, designers, community and arts organisations also ran independent temporary projects in unexpected places. The need for temporary urbanism and the desire for public participation led to the establishment of Life in Vacant Spaces ${ }^{7}$ in 2012 as a site-broker for creative, temporary urban projects in the city.

Two examples provide an idea of the diversity of these urban interventions. In a city suddenly bereft of performance venues, Gap Filler's open-air, coin-operated Dance-omat ${ }^{8}$ provided a surprising and accessible space for anyone to dance to their own music. Greening the Rubble's Nature Play Park ${ }^{9}$ not only gave children a safe and welcoming space to play in an otherwise inhospitable demolition zone, it exemplified the city as people wanted it to be: greener, more natural, human-scaled, child-oriented and accessible. Christchurch's temporary urban and art projects weren't confined to people employed by these organisations. The groups and individuals engaging in emergent urban and artistic practice welcomed public participation and actively sought collaboration and volunteer involvement.

\footnotetext{
${ }^{2}$ http://architecturenow.co.nz/articles/the-final-blueprint-for-a-new-christchurch/. Accessed October I, 2017.

${ }^{3}$ https://teara.govt.nz/en/zoomify/46379/eastern-suburbs-red-zone. Accessed October I, 2017.

${ }^{4}$ I follow Rebecca Solnit's definition of 'citizen': “members of a city or community, not people in possession of legal citizenship in a nation. Solnit, A Paradise Built in Hell, Penguin 2009, 2.

${ }^{5}$ http://gapfiller.org.nzl. Accessed October I, 2017.

6 http://greeningtherubble.org.nzl. Accessed October I, 2017.

${ }^{7}$ http://livs.org.nz/. Accessed October I, 2017.

${ }^{8}$ http://gapfiller.org.nz/project/dance-o-mat/. Accessed October I, 2017.

9 http://greeningtherubble.org.nz/our-projects/nature-playl. Accessed October I, 2017.
} 
There's something galvanising and socially transformative about a natural disaster.

Rebecca Solnit writes about this in her book A Paradise Built in Hell. "What is this feeling that crops up during so many disasters? ....an emotion graver than happiness but deeply positive... [that provides us with] a glimpse of who else we ourselves may be and what else our society could become". ${ }^{10}$ Solnit calls it a "reversion to improvised, collaborative, cooperative, and local society"." Christchurch people felt and experienced this. It is a desire, willingness and fresh capacity to create meaningful community, and with it, meaningful places.

The groundswell of social creativity and urban action knitted together new networks of people. In late $201 \mathrm{I}$ and early 20I2, two people on either side of the Tasman Sea independently suggested that Christchurch was a ripe place to establish a festival of temporary architecture: Christchurch experimental theatre producer and actor, George Parker (Free Theatre), and Melbourne-based futurist Stuart Candy (then at Arup). Uwe Rieger, Associate Professor of Architecture at the University of Auckland, proposed a headline event for the nascent festival based on installations designed and fabricated by tertiary students in architecture and design. A steering group of artists, designers, lecturers and those active in the 'transitional movement' was swiftly assembled. We began to formalise a structure. As an under-employed architectural historian with a passion for public engagement in architecture and urbanism, I was elected to direct the festival. Uwe Rieger brought a wealth of experience conceiving, teaching and producing I:I fabrications as public events, and others had a background in theatre, festivals and dance parties. Our inexperience at producing complex events at an urban scale (in a disaster zone) was compensated for by an energy spurred by the physical, cultural and political context. We were spurred on by the encouragement we received from prospective collaborators. And so FESTA was born.



Figure 2. Tens of thousands of people reclaimed the central city during LUXCITY at FESTA 2012. Photo: Bridgit Anderson.

\footnotetext{
${ }^{10}$ Solnit, 2009, 5-6.

"Solnit, 2009, 10.
} 
The opening night for the inaugural Festival of Transitional Architecture (FESTA) in October 2012 was Studio Christchurch's LUXCITY. Against the dark background of the red zone 16 architectural installations by 350 design and architecture students from across New Zealand created a fleeting and enchanting urban atmosphere. An estimated 30,000 people filled this city made from light for one night making it a moving and historic event.
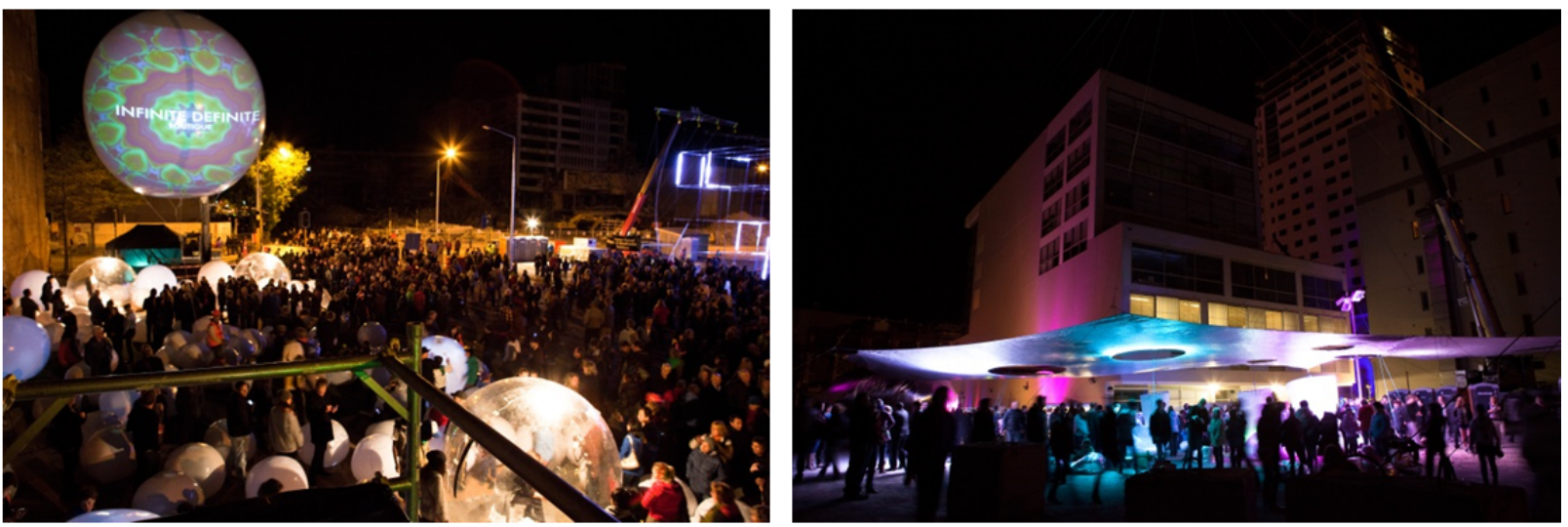

Figure 3 (left). In Your Face, a collaboration between local fashion boutique Definite Indefinite and University of Auckland students from the School of Architecture \& Planning for LUXCITY, FESTA 20 12. Photo: Bridgit Anderson.

Figure 4 (right). Murmur was a thin, fragile canopy suspended from a crane so it shifted and swayed with the wind. Designed by students from the School of Architecture \& Planning,

University of Auckland for LUXCITY, FESTA 2012. Photo: Bridgit Anderson.
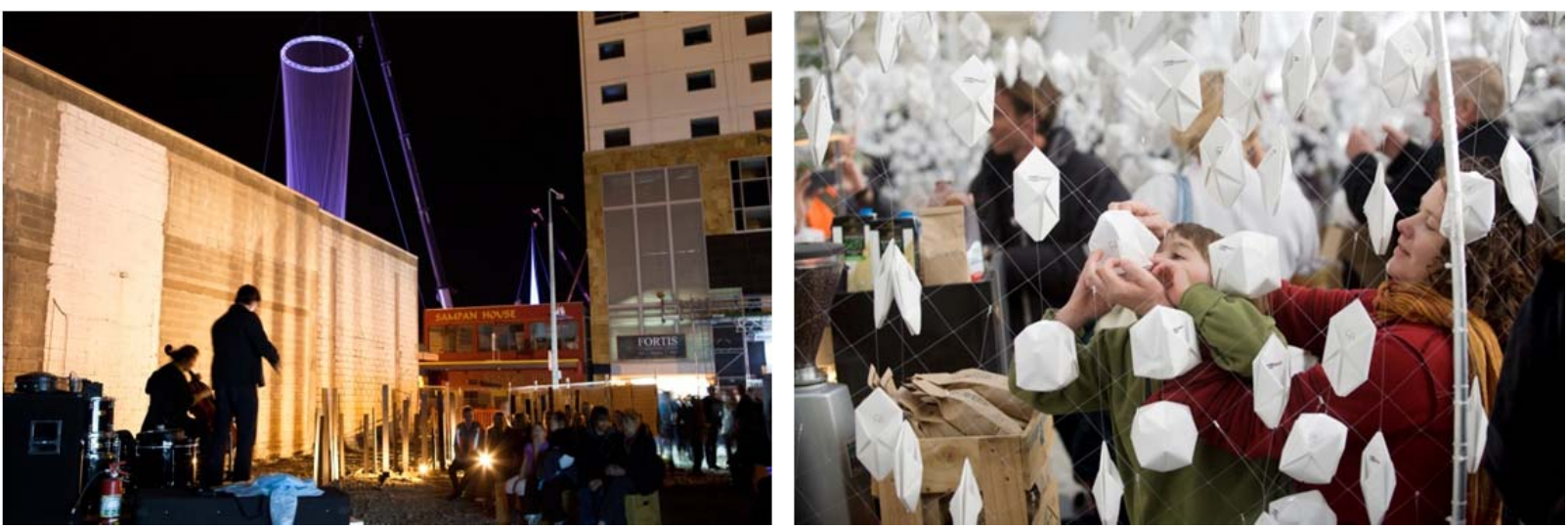

Figure 5 (left). CPIT installation 'Illusion' created a secluded atmosphere for live jazz at LUXCITY, FESTA 2012. Photo: Bridgit Anderson.

Fugure 6 (right). AUT Spatial Design students created Halo, a human-scaled semi-circular arcade hung with glowing paper lanterns which were inflated by the breath of participants. Photo: Mark Gore.

LUXCITY, a city made from light for one night, was the headline event for the inaugural FESTA in October 2012. Set against the darkness of the evacuated central city, 350 design and architecture students from five New Zealand tertiary institutions designed and fabricated 16 architectural installations using light as their primary medium. The equipment that was demolishing the city by the day was used to provide structural support to LUXCITY's installations. Achieving an urban scale relied on sponsors donating machinery and expertise to run hundreds of thousands of dollars of demolition equipment 
for free. With a backdrop of half demolished, damaged and inaccessible buildings, cranes, high-reach and telehandlers suspended an ephemeral and delicate architecture.

The spectacle of student-created live projects was fundamental to the event. However, LUXCITY was more than an exhibition of student design bravura. The event also involved the 'stuff of the urban scene' that was then absent from Christchurch's urban centre. We brought in collaborators for each studio project, who activated the installation sites with bars and cafes, performances, an all-ages dance venue, a live fashion show and a night market. The other key participants in LUXCITY were the public - an overwhelming number of people poured in to visit that night; crowd estimates ranged from 20,00030,000 .

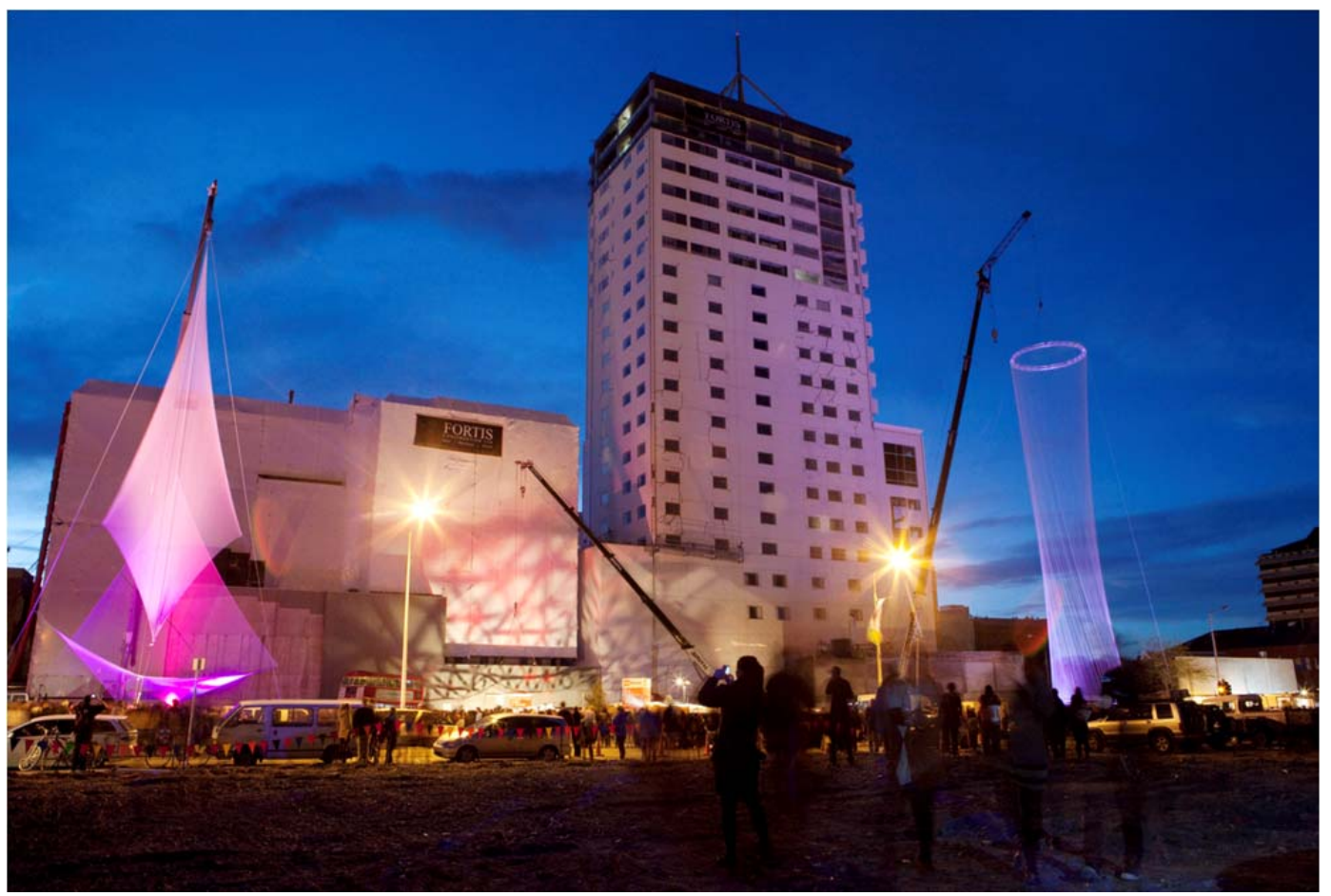

Fugre 7. LUXCITY's principal medium was light and many of the projects used large-scale demolition machinery to support and suspend the installations. The machinery was generously donated by local companies Smith Crane \& Construction, Leighs Construction, and Ceres Environmental. FESTA 2012.

Photo: Mark Gore.

Having a participating audience made LUXCITY's promise of instant urbanity real through the crowd's interaction with the installations and activities, revelling in LUXCITY, making it dense and alive. For many people attending LUXCITY, it was the first invitation they had had to come into the city since the February 2012 earthquake 20 months earlier. It was an intensely emotional experience for many - as their attention wasn't first granted to the installations but to the once-familiar sights and places of their central city under the process of demolition and removal. A sense of grief and loss soon gave way to delight and amazement, as people had chance encounters with each other on the street, and became absorbed by the surreal and joyful presence of the architectural installations and urban activities. In that one night, Christchurch transformed to become what all cities are: an intensification of life. It might be too much to say LUXCITY felt messianic - but it briefly 
brought light to darkness; hope and joy to a period of uncertainty and grief; celebration and a certain defiance to a tense political and social environment.

LUXCITY established the model and a 'signature' for FESTA's future headline events the bringing together of tertiary student live project installations with local businesses and arts and youth organisations. Over the festival weekend a wider programme brings together intimate and smaller events, drawing on Christchurch 's new culture of collaborative temporary urbanism. FESTA co-founder Barnaby Bennett (UTS, Sydney) describes this "second kind of activity at FESTA [as] a programme of smaller public events such as workshops, book launches, exhibitions, openings, art projects, talks, walking tours, and other activities that enable engaged experiences to the public. Through these other events FESTA has developed networks and relationships with many other organisations in the city. FESTA has acted as a catalyst for the transitional movement and many of the major transitional projects have been planned by, for, or launched at FESTA."'2

From its conception, FESTA adapted to the circumstances of the city. Politics, place and theatre expanded the range and ambition of the headline event for FESTA 2013. Free Theatre's Canterbury Tales used the activities and rituals that bring people together in an "active search for a sense of community". This time six student installations, six performance collectives, and a procession of giant puppets transformed the night-time emptiness of the city's most prominent public spaces. Production lead George Parker described it as "Taking Chaucer as a point of reference, in so far as it brings together the seemingly high and the low, the noble and ignoble, [to create] a carnivalesque mixing up of social roles and urban environments." 3 Canterbury Tales was a far more consciously and deliberate political statement against the command and control of central government than LUXCITY. It used artistic collaboration, performance and site-specific temporary architecture as ways to sustain the openness, spontaneity and community warmth of post-disaster settings that Solnit recognises as fleeting.

In 2013 Christchurch's 'transitional' culture was flourishing, with participants from a range of creative disciplines. It was also drawing international attention with coverage from Lonely Planet and the New York Times. This culture provided a strong and distinctive associate programme of events and projects over FESTA weekend to accompany Canterbury Tales. The programme included a tiny mobile cinema made from an advertising trailer, Agropolis, a new transitional urban farm, and a mobile sauna in a tent. 'The Future Will be Live' was the theme for FESTA's third outing in 2014: how small, experimental and temporary projects in the city could be used to imagine, speculate on and present live experiences of the future. For the major event CityUps, installations were both physical and digital, with digital speculations anchored in physical space via an augmented reality app. The future city was presented not just as a technological leap but also with structures and opportunities that allowed for new social relationships. As well as 13 architectural installations, City Ups included students working in visual arts practice that drew on relational aesthetics, and drew artist practitioners from Wellington who activated public spaces with street games that recreated those immediate postearthquake conditions of strangers working co-operatively and having shared experiences

\footnotetext{
${ }^{12}$ Barnaby Bennett, draft PhD Thesis in Architecture, University of Technology Sydney, 2017, chapter 4.

${ }^{13}$ George Parker, 'Time to bring an empty city to life', The Press, 21 October 20I3, http://www.stuff.co.nz/the-press/opinion/perspective/9309967/Time-to-bring-an-empty-city-to-life.
}

I 82 | The Journal of Public Space, 2(3), 2017 | Special Issue | ISSN 2206-9658

(C) Queensland University of Technology 
of joy and celebration. CityUps imagined future longed to learn from and carry forward possibilities from the recent past.

Solnit's thesis recounts the flourishing of alternative social behaviour and experiments in the absence of conventional structures and organisations in post-disaster situations. Gradually FESTA has become more conventionally structured in its organisation. The decision to become biennial in 2015 and present FESTA only in even years was borne of a desire to make the event more considered, less random and hurried in its production. In response to a broader call within the city for less 'transitional' activity and an increased focus on a 'permanent' recovery for the city, FESTA deliberately became more strategic. This was seen in the preparation of a strategic plan for the 2016 event, which considered the outcomes for the 'four bottom lines' (cultural, economic, environmental, social). This change is described by Solnit's question - as "emergent groups turned established... [can they] function with the same level of improvisation/creativity that once characterised their actions?" 4 At its core, FESTA is still conceived as an event that seeks new ways to create meaningful connections between and within communities and urban place in a cooperative and open way. We understand FESTA as providing a platform for city-makers and citizens to "imagine and experience Christchurch differently" and to create opportunities for the denizens of Christchurch to get directly involved in the remaking of their city.

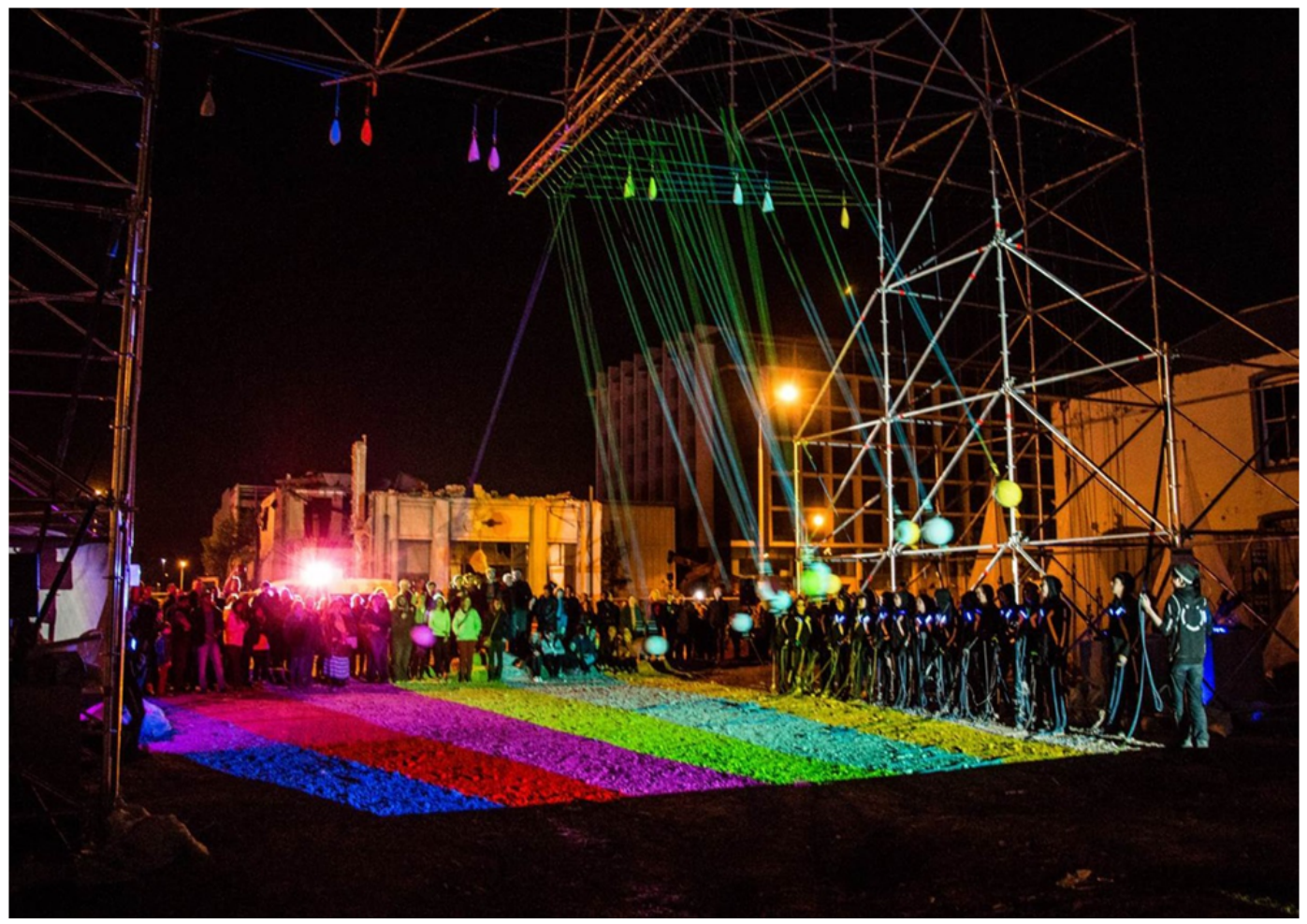

Figure 8. University of Auckland School of Architecture and Planning, $\mathrm{CHCH} 206 \mathrm{I}$, CityUps, FESTA 2014. Photo: Erica Austin.

The city we wanted to imagine and experience with FESTA 2016 was one that was more sustainable and with greater social connection. 'We Have the Means' drew on the pioneering approach to sustainable design and city-making developed by Superuse

\footnotetext{
${ }^{14}$ Solnit, 2009, 302
} 
Studios ${ }^{15}$ in Rotterdam. Adopting Superuse Studios's systems-based approach to sustainable design challenged students and project creators to use waste streams as physical materials for the basis of their project designs. While Superuse Studios design permanent buildings from reused materials, for 2016's major event Lean Means student studios needed to translate that resourceful design practice into temporary installations using lightweight and low-value reused materials. Plastic bottles and bags, expired lightbulbs and cardboard tubes were amongst the materials sourced and manipulated to create an experience of a resourceful city. Activation of these installations included the local social enterprise Rekindle ${ }^{16}$, which staged public workshops and demonstrations of resourcefulness, taking underutilised and discarded natural waste materials and crafting useful everyday items from them.
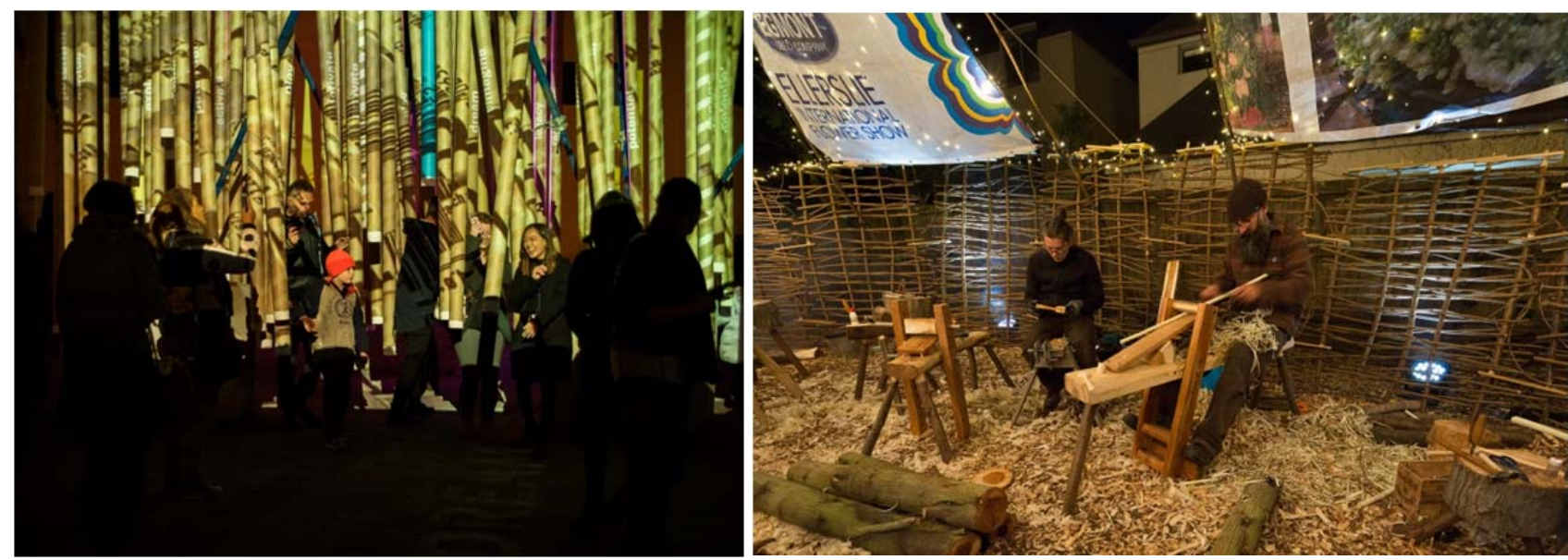

Figure 9 (left). Massey College of Creative Arts with Julia Morison, Pipe Dreaming, Lean Means, FESTA 2016. Photo: Peanut Productions.

Figure 10 (right). Ara School of Architectural Studies with Rekindle, Hence/Zero Waste Ōtautahi, Lean Means, FESTA 2016. Photo: Bridgit Anderson.

In the years since 20I I, Christchurch's immediate disaster management phase gave way to recovery, and in 2017, it is now in a phase officially labelled 'regeneration'. As the city rebuilds, is there a future for FESTA in a non-disaster urban context? Through FESTA we understand the city best as a public good. While there remains a demand and a desire to sustain FESTA's practice of working with hundreds of architecture and design students to create a spectacle that attracts crowds in their thousands, we continually question what the Festival is and who it is for. The circumstances that birthed FESTA have changed.

Disaster is no longer acute, the city is no longer on life support (or sliding to its grave), but our desire for creating meaningful community and meaningful places endures. How can a biennial festival continue to test and trial what that means and how it can happen? For our 2018 edition we're teasing out ideas of inclusion and diversity in city-making, questions about who a city is made for and who is involved in its making. FESTA remains sustained by a desire for "purposefulness, meaning, involvement and community" and for "an affection that is not private and personal but civic: the love of strangers for each

\footnotetext{
${ }^{15} \mathrm{http}: / /$ superuse-studios.com/. Accessed October I, 2017.
}

${ }_{16}$ https://www.rekindle.org.nzl. Accessed October I, 2017.

I 84 | The Journal of Public Space, 2(3), 2017 | Special Issue | ISSN 2206-9658

(C) Queensland University of Technology 
other, of a citizen for his or her city, of belonging to a greater whole, of doing the work that matters." 17

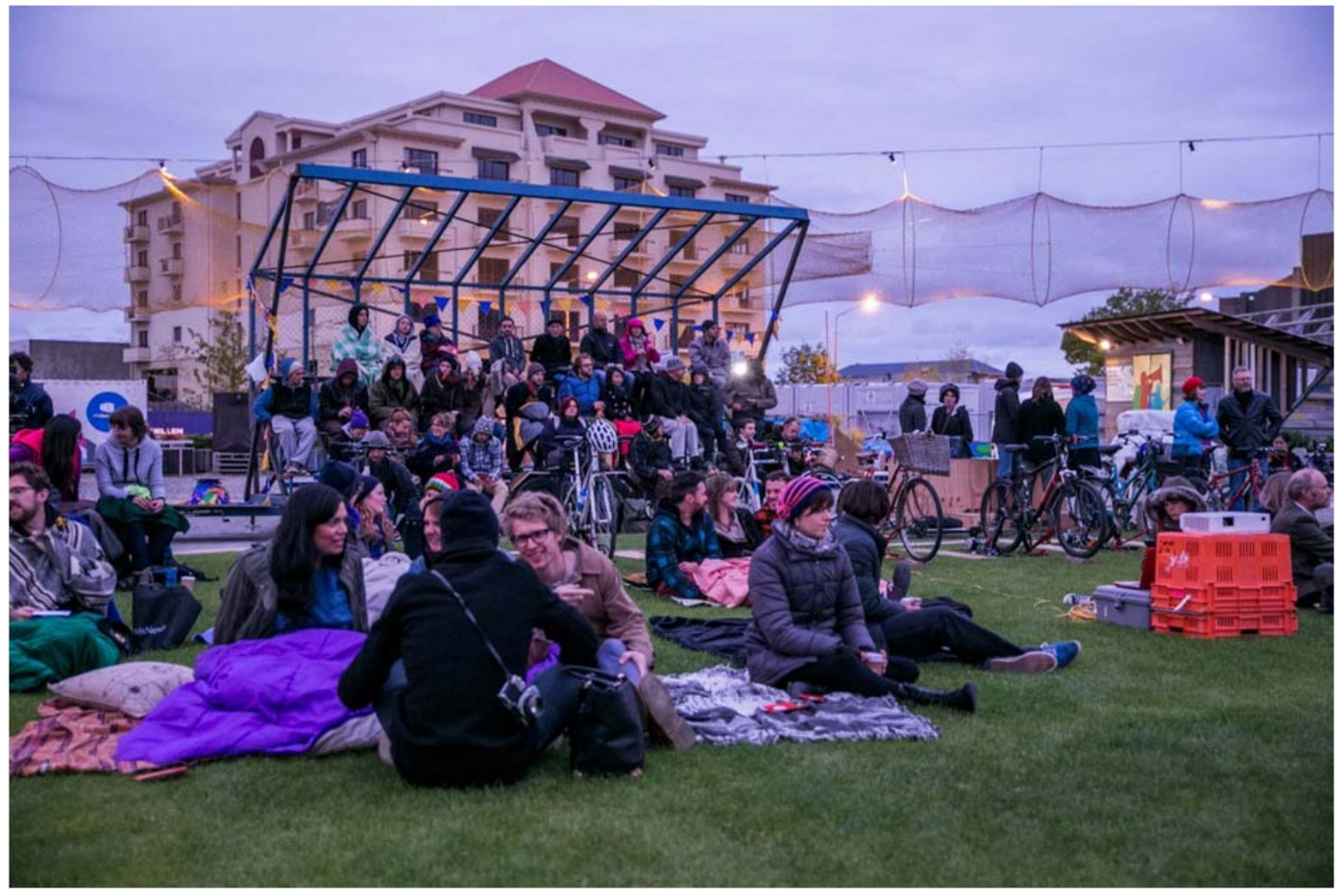

Figure II. Gap Filler's Cycle Powered Cinema and Grandstandium at FESTA 2014. Photo: Erica Austin.

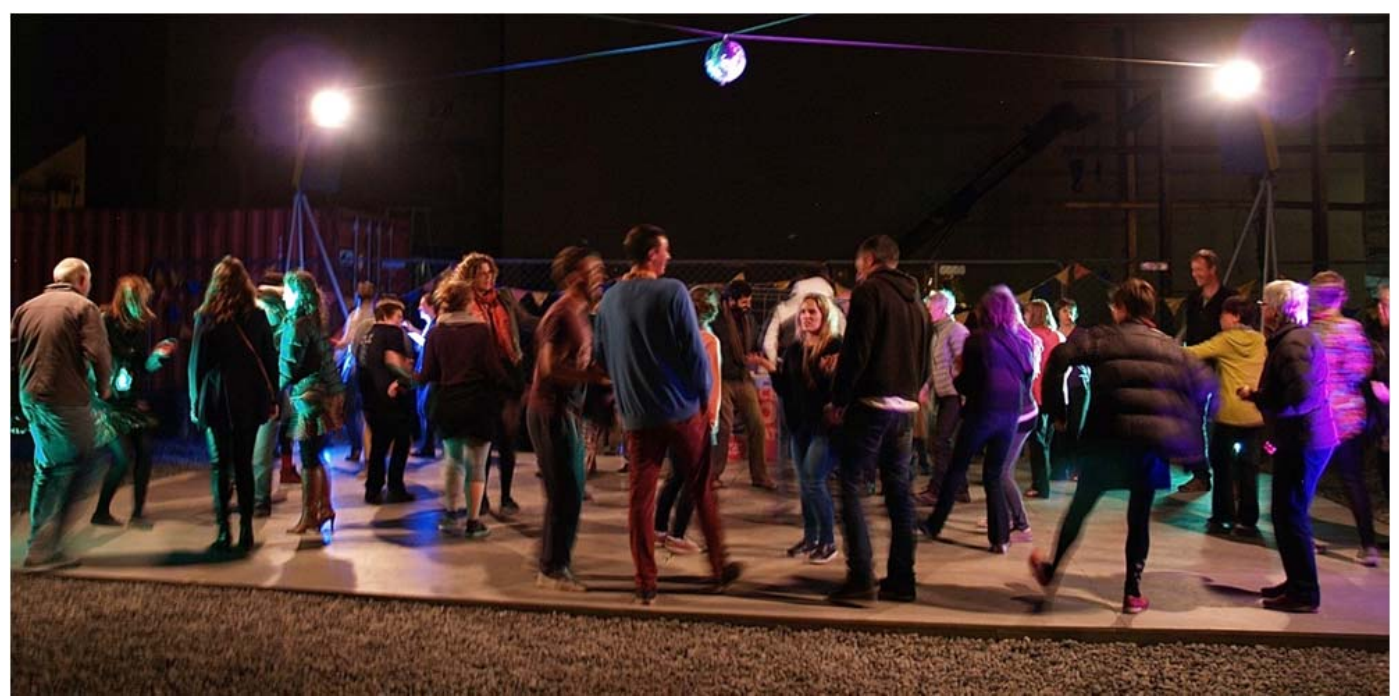

Figure I2. DJs Cease + Desist with Gap Filler, SuperWow Disco at the Dance-o-mat, FESTA 2014. Photo: Chloe Waretini.

\footnotetext{
${ }^{17}$ Solnit, 2009, 306.
} 

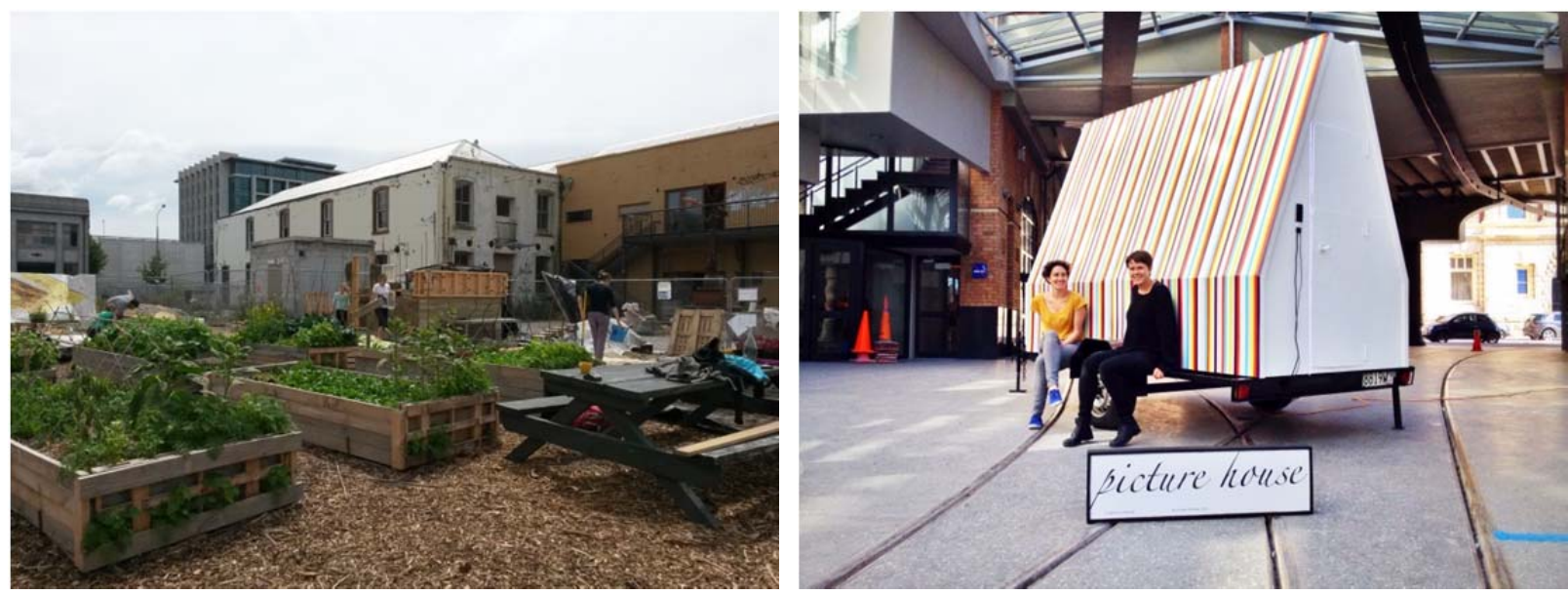

FESTA is an annual transitional urbanism festival with a programme of multi-disciplinary innovative, creative projects, events and community-based activities that build and strengthen the passion and involvement of local communities in the regeneration of the central city.

Figure I 3 (left). Agropolis urban farm was launched during FESTA 2013 and hands-on learning opportunities were held there every day of the Festival. Photo: Jessica Halliday.

Figure 14 (right). Makeshift's Picture House, a cinema for two on wheels, made its debut at FESTA 2013 where it screened a short film every day of the Festival on the sites of former cinemas around Cathedral Square. Photo: Ed Lust.


Figure 15 (left). 100 people join Gap Filler to celebrate the activation of their Sound Garden project during FESTA 2013. Photo: Erica Austin.

Figure 16 (right). Fabricio Fernandes' Nomadic Sauna with its pine wood-structured, canvas-covered dome and pot-belly stove popped up on Manchester St for FESTA 20I3. Photo: Ed Lust.

\section{To cite this article:}

Halliday, J. (2017), FESTA Festival of Transitional Architecture in Christchurch, New Zealand. The Journal of Public Space, 2(3), Special Issue, I77-I86, DOI: I0.5204/jps.v2i3.I26

This article has been accepted for publication in The Journal of Public Space. Please see the Editorial Policies under the 'About' section of the journal website for further information.

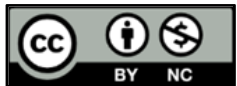

This work is licensed under a Creative Commons Attribution - Non Commercial 4.0

International License https://creativecommons.org/licenses/by-nc/4.0/

| 86 | The Journal of Public Space, 2(3), 2017 | Special Issue | ISSN 2206-9658

(C) Queensland University of Technology 